\title{
Selection from Gonococci Grown in vitro of a Colony Type with some Virulence Properties of Organisms Adapted in vivo
}

\author{
By C. W. PENN, D. R. VEALE AND H. SMITH \\ Department of Microbiology, University of Birmingham, Birmingham BI5 $2 T T$
}

(Received I November 1976)

\section{SUMMARY}

Gonococci from subcutaneously implanted chambers in guinea pigs produced, on agar, more than $95 \%$ small colonies showing a 'double highlight' (DH) effect in oblique reflected light combined with transmitted light. Laboratory strains of gonococci produced some $\mathrm{DH}$ colonies, but others showed a single highlight $(\mathrm{SH})$ or no highlight $(\mathrm{NH})$. Selection of $\mathrm{DH}$ colonies and comparison of their organisms with gonococci grown in vivo and with those from SH colonies, showed that the DH character was associated with high infectivity for guinea-pig chambers, resistance to killing by human phagocytes and heavy pilation. Furthermore, $\mathrm{DH}$ colonies were found in the first culture of three fresh samples of urethral pus. Thus, the DH colony characteristic may be a more reliable criterion of pathogenicity of gonococcal isolates than systems used previously. There were, however, some differences between the gonococci grown in vivo and the DH colony types. The gonococci grown in vivo and cultured once on solid medium possessed one or two antigens which differed from those of $\mathrm{DH}$ (or $\mathrm{SH}$ ) colonies. They also formed smooth suspensions (which separated slowly) in saline, compared with the rough suspensions (which separated quickly) formed by gonococci from $\mathrm{DH}$ (or $\mathrm{SH}$ ) colonies. Finally, the organisms grown in vivo were resistant to killing by human serum whereas the DH (and SH) colony types were susceptible; the resistance of the organisms grown in vivo was lost during one subculture on agar suggesting that the property is a phenotypic characteristic. Hence, in addition to selecting DH colony types the conditions in vivo produce organisms which differ, probably phenotypically, from cultured organisms.

\section{INTRODUCTION}

There is increasing evidence that gonococci grown in vivo are different from those grown on laboratory media. Gonococci from human urethral pus infected humans more easily than gonococci grown in vitro (Mahoney et al., 1946), were more resistant to killing by human serum (Ward, Watt \& Glynn, 1970) and had more distinctly layered cell walls and fewer pili (Novotny, Short \& Walker, 1975). Gonococci grown in subcutaneously implanted chambers in guinea pigs (Veale et al., 1975) were more infective for guinea-pig chambers and more resistant to killing by human serum and by human phagocytes than the parent strain grown in vitro (Penn et al., I976; Witt et al., 1976a). Also, they were variably pilated and produced one or two antigens different from those formed by organisms grown in vitro. These differences between strains grown in vivo and in vitro might have resulted either from selection in vivo of more virulent types from the population, or from phenotypic change (Smith, 1972). Phagocytosis experiments with human polymorphonuclear (PMN) phagocytes and a pilated, small-colony-forming strain (BS) grown in vitro indicated that selection occurs, since after rapid initial intracellular killing there was prolonged survival of a small 
proportion of the original population, a survival comparable to that seen for organisms grown in vivo (Witt et al., 1976a).

Examination of colonies produced by organisms grown in guinea-pig chambers showed that in addition to being smaller than colonies of the parent laboratory strain (Penn et al., I976), a 'double highlight' (DH) effect was observed in oblique reflected light combined with transmitted light. The parent strain (BS) also produced some colonies which showed the $\mathrm{DH}$ effect. The technique for observing this effect is described here and the properties of gonococci separated from the parent strain by this marker are compared with those of: (i) gonococci found in colonies formed by the parent strain which did not show the DH effect; (ii) organisms from guinea-pig chambers. Two additional strains of gonococci that had been subcultured many times in vitro were examined for DH colonies directly and after passage through guinea-pig chambers; for one isolate, the properties of gonococci grown both in vivo and in vitro were compared with corresponding organisms from the Bs strain. Finally, primary cultures of three fresh samples of urethral pus were examined for DH colonies before and after passage through guinea-pig chambers; for one sample, the properties of gonococci from such colonies were compared with corresponding organisms from the BS strain. The results indicated that phenotypic change probably occurs in vivo, as well as selection.

\section{METHODS}

Strains of Neisseria gonorrhoeae. Strain BS, a pilated, small-colony-forming type resembling Kellogg type 2 was described by Veale et al. (1975). After three passages in guinea-pig chambers and freezing in liquid nitrogen as described by Penn et al. (1976) it was designated BS3 if used in tests directly after thawing, and BS3 (agar) if grown once on solid medium (Penn et al., 1976). Sometimes, for phagocytosis tests, BS3 received two further passages through guinea-pig chambers and was then used directly after being separated by differential centrifugation as described by Witt et al. (1976a); in this case it was designated BS5.

Strain As, a pilated, small-colony-forming type resembling Kellogg type I was described by Veale et al. (1975). It had been subcultured many times since the primary isolation. When treated in a similar manner to BS it yielded AS3 and AS3 (agar) corresponding to $\mathrm{BS}_{3}$ and $\mathrm{BS}_{3}$ (agar).

Strain DS was another pilated, small-colony-forming laboratory strain which was treated as described for BS to yield DS3 and DS3 (agar).

Strains CS, ES and FS were isolated from separate fresh samples of urethral pus by plating the pus on AG agar (Penn et al., 1976); details are described in Results.

All strains were stored in liquid nitrogen in cryo-protective medium as described by Penn et al. (1976).

Medium and growth conditions. Haemoglobin agar was used to determine viable counts [dilutions were made in BBL Trypticase Soy Broth (TSB)] and for growing gonococci for antigen extraction (Penn et al., 1976). Transparent AG agar (Veale et al., I 975; Penn et al., I976) was used in triple-vented plastic Petri dishes (Type IOIVR, Sterilin, Teddington, Middlesex) for subculture and identification of colony type. For the latter purpose, 20 to $25 \mathrm{ml}$ of medium was used per plate. Plates (closed and stacked in groups of three) were dried for $24 \mathrm{~h}$ at $37^{\circ} \mathrm{C}$ in a room with circulating air. If not used immediately thereafter, they were stored in a refrigerator for not more than 4 days. Cultures were grown for 20 to $24 \mathrm{~h}$ at $37^{\circ} \mathrm{C}$ in candle extinction jars.

Colony morphology. Attempts were made to use the lighting system of Kellogg et al. (1963, I 968): namely diffuse, angled (extent unknown), transmitted light combined with top 
lighting at $15^{\circ}$ to the horizontal. Using this method the colonial appearances described by Kellogg et al. (1963, I968) were difficult to recognize and differentiation of colony types was unreliable. The method of Jephcott \& Reyn (I97I) required specialized apparatus. The following method was devised and proved satisfactory.

Colonies were examined after 20 to $24 \mathrm{~h}$ growth at $37^{\circ} \mathrm{C}$ on $\mathrm{AG}$ agar with a LeitzDialux microscope using Kohler illumination for transmitted light and a 4/0.I 2 objective. Reflected light was provided by a beam from a separate pillar-mounted microscope lamp (Intense model, Vickers Instruments, York) set at about $40^{\circ}$ to the horizontal above the plate. The transmitted light showed colour, granularity and entirety of edge, while the reflected light indicated the nature of the surface and provided the highlights which were characteristic of some colony types.

Subcutaneously implanted guinea-pig chambers. Male Dunkin-Hartley guinea pigs (grade 2; Olac, Banbury, Oxfordshire; $600 \mathrm{~g}$ ) received two or four chambers $(4.5 \mathrm{ml})$ which were implanted, inoculated and sampled as described by Veale et al. (1975).

Observation of pili by electron microscopy. This was described by Penn et al. (1976).

Test for resistance to killing by fresh human serum. This was a modification of that described by Penn et al. (1976). A pool of freshly collected human serum (from eight persons) was frozen at $-70^{\circ} \mathrm{C}$ until required. Twofold dilutions of thawed serum $(0.25 \mathrm{ml}$ in PBS; Penn et al., 1976) and suspensions of the gonococcal strain ( $0.025 \mathrm{ml}$ TSB containing about 250 viable gonococci) were placed in $98 \times 12 \mathrm{~mm}$ glass tubes with loose metal caps and incubated in air at $37^{\circ} \mathrm{C}$. After $30 \mathrm{~min}$, samples $(0.2 \mathrm{ml})$ were withdrawn for viable counts which were compared with those for control tubes containing heated $\left(56{ }^{\circ} \mathrm{C}\right.$, $30 \mathrm{~min}$ ) serum. The lowest dilution of serum that allowed $50 \%$ survival compared with the counts of control tubes was noted. For at least three tests on every strain examined, the end-point did not vary by more than one twofold dilution.

Estimation of approximate minimal infective dose (m.i.d.) for subcutaneous chambers. This was as described by Penn et al. (1976).

Examination of surface antigens by gel diffusion. Surface antigens of gonococci were washed off in TSB (Penn et al., 1976) and analysed by double gel diffusion against antiserum raised in guinea pigs by chamber infection with strain BS3 and used before and after adsorption with strain BSDH (agar) (see below), as described by Penn et al. (I976).

Test for resistance to intracellular killing by the phagocytes of human buffy coat. This was as described by Witt, Veale \& Smith (I976b) and Witt et al. (I976a), except that the inoculum of gonococci was lower (about I organism to Io PMN phagocytes). In most experiments (those in Table 3), the gonococci were conditioned $\left(\mathrm{r} \mathrm{h}, 37^{\circ} \mathrm{C}\right.$ ) in the medium used for phagocytosis before the phagocytes were added as described by Witt et al. (1976a). However, in a few experiments the gonococci were mixed with the phagocytes without preliminary conditioning in the medium, since this procedure was used in the original comparison of the strain from guinea-pig chambers with the parent BS strain (Witt et al., 1976a). Electron microscopy was used to check that the majority of cell-associated gonococci in phagocyte deposits were in fact intracellular as described by Witt et al. (1976a,b).

\section{RESULTS}

The 'double highlight' form of colonies of strain $\mathrm{BS} 3$ and the presence of such colonies among those produced by the parent strain BS

When strain BS3 was first cultured on agar [BS3 (agar)], more than $95 \%$ of colonies had the following form. First, as noted before (Penn et al., 1976), they were smaller and more 


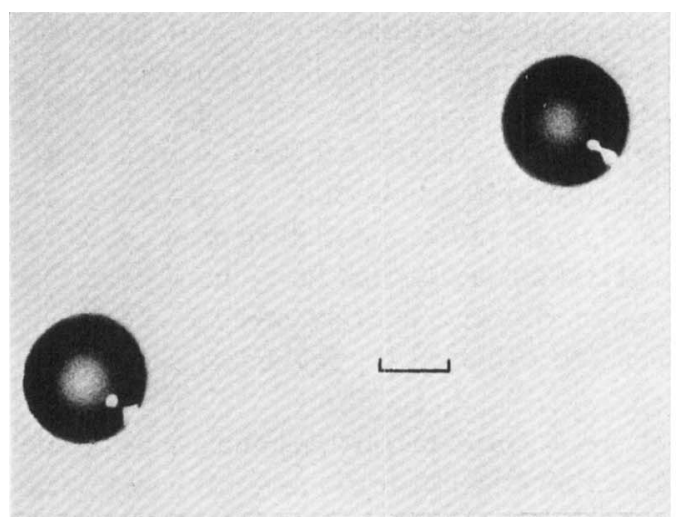

Fig. I

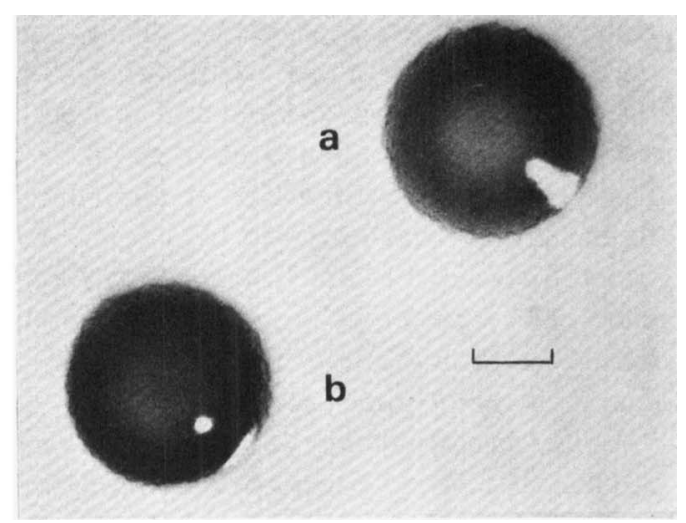

Fig. 2

Fig. I. Colonies of BS3 (agar) viewed by transmitted and reflected light. Note the double highlight. Bar marker represents $0.1 \mathrm{~mm}$.

Fig. 2. Colonies of BSSH (a) and BSDH (b), viewed by transmitted and reflected light. Note the single highlight on colony (a) and the double highlight on colony (b). Bar marker represents $0.1 \mathrm{~mm}$.

variable in size than colonies produced by the parent strain. Second, the edge highlight produced by reflexion of the microscope lamp set at $40^{\circ}$ to the horizontal was split into two regions (Fig. I); such colonies were called DH colonies. In this illumination system they had shiny surfaces with little granularity, a gold centre (diameter about one-third to onehalf of the colony diameter) and a dark, almost black, periphery (possibly due to refraction of transmitted light) with an entire edge.

When colonies of the parent strain (BS) were examined, the majority ( 80 to $90 \%$ ) showed an edge highlight of reflected light which was not divided. These were called single highlight (SH) colonies (Fig. 2, colony a). They were slightly larger and more granular than $\mathrm{DH}$ colonies and had a larger central gold area and a lighter peripheral zone. The surface was reminiscent of orange peel and the edge was finely serrated and sometimes grossly irregular. They varied from dark gold to straw colour and when the latter occurred the colonies were less granular. Among these $\mathrm{SH}$ colonies, $\mathrm{DH}$ colonies could be found (Io to $20 \%$ ) and these were similar to those produced by BS3 but were slightly larger and had a less entire edge (Fig. 2, colony b). A few large colonies were seen that did not have a highlight and were uniformly pale straw colour, non-granular and with an entire edge; these were designated no highlight $(\mathrm{NH})$ colonies.

Variations in growth conditions, such as moisture content of the medium, density of colonies, distance from confluent growth and duration of incubation, caused deviations from the descriptions above. SH colonies sometimes had highlights partially separated into keyhole shapes and the highlights on DH colonies sometimes touched. The development of DH character required 20 to $24 \mathrm{~h}$ incubation and might not occur in colonies near confluent growth. By $48 \mathrm{~h}$ the DH effect had disappeared and sector mutants were observed. Thus it is important when comparing colonies to keep to the standard growth conditions stipulated in Methods. Occasionally colonies not fitting any of the above descriptions were also seen.

On subculture of single colonies from both BS3 (agar) and the parent strain, the types were unstable. Dissociation from $\mathrm{DH}$ to $\mathrm{SH}$ or $\mathrm{NH}$ was the predominant trend and fre- 
Table I. Resistance to killing by fresh human serum_of gonococcal types derived from parent strains $\mathrm{BS}, \mathrm{AS}$ and $\mathrm{CS}$

\begin{tabular}{|c|c|c|c|}
\hline & \multicolumn{3}{|c|}{$\begin{array}{c}\text { Lowest dilution of fresh human } \\
\text { serum for } 50 \% \text { survival }\end{array}$} \\
\hline Strain & Test I & Test 2 & Test 3 \\
\hline BS3 & $<\mathrm{I}: \mathrm{I}$ & $<\mathrm{I}: \mathrm{I}$ & $I: I$ \\
\hline BS3 (agar) & $1: 32$ & $1: 32$ & $1: 32$ \\
\hline BSDH & $1: 16$ & $\mathrm{I}: 8$ & $1: 8$ \\
\hline BSSH & $1: 8$ & $I: I 6$ & I : 16 \\
\hline AS3 & $<\mathrm{I}: \mathrm{I}$ & $1: 1$ & $<\mathrm{I}: \mathrm{I}$ \\
\hline As3 (agar) & $1: 32$ & $\mathrm{I}: \mathbf{3 2}$ & I : 32 \\
\hline ASDH & $I: 16$ & $\mathrm{I}: \mathrm{I} 6$ & $\mathrm{I}: 8$ \\
\hline ASSH & I : 16 & I : I 6 & I : 8 \\
\hline $\mathrm{Cs} 3$ & $<\mathrm{I}: \mathrm{I}$ & $<1: 1$ & $<\mathrm{I}: \mathrm{I}$ \\
\hline cs3 (agar) & < I:I & $<\mathrm{I}: \mathrm{I}$ & $<\mathrm{I}: \mathrm{I}$ \\
\hline CSDH & $<\mathrm{I}: \mathrm{I}$ & $<1: I$ & I : 2 \\
\hline $\mathrm{CSSH}$ & $<\mathrm{I}: \mathrm{I}$ & $<\mathrm{I}: \mathrm{I}$ & $<\mathbf{I}: \mathbf{I}$ \\
\hline
\end{tabular}

quently 5 to $10 \%$ of the progeny from a single colony were of a different type from the parent. Occasionally a few DH colonies arose from a SH parent.

\section{Comparison of properties of organisms from $\mathrm{DH}$ and $\mathrm{SH}$ colonies of strain $\mathrm{BS}$} with those from strain $\mathrm{BS} 3$

$\mathrm{DH}$ and $\mathrm{SH}$ colonies were selected from strain BS and streaked on fresh AG agar. After incubation at $37^{\circ} \mathrm{C}$ for 20 to $24 \mathrm{~h}$ and checking that more than $90 \%$ of the isolated colonies were of the same type, these colonies were suspended in TSB and cryo-protective media (Penn et al., 1976) and frozen in liquid nitrogen as stock cultures of strains BSDH and BSSH. These strains were compared with BS3 (the strain passaged in guinea-pig chambers) directly after thawing or after one subculture on AG agar (when at least $90 \%$ of the colonies were of the appropriate type). Thus, in the tests below, BSDH and BSSH used directly after thawing correspond with BS3, and BSDH (agar) and BSSH (agar) with BS3 (agar).

Pilation. At least $90 \%$ of over 100 observed organisms of BS3 (agar) and BSDH (agar) bore pili. The mean number of pili borne by Bs3 (agar) organisms was $25.5 \pm 16.3$ S.D. and by BSDH (agar) organisms was $20 \cdot \mathrm{I} \pm \mathrm{I} 3.8$ S.D.; pili were counted on 20 randomly selected diplococci that were at least three diameters away from other diplococci. In contrast, less than $10 \%$ of over 100 observed organisms of BSsH (agar) bore pili and they had less than 5 pili per organism. The few $\mathrm{NH}$ colonies obtained from the parent strain Bs contained non-pilated organisms.

Resistance to killing by fresh human serum. In at least three tests the limiting dilutions of the stock sample of human serum which allowed $50 \%$ survival of $\mathrm{BS}_{3}, \mathrm{BS} 3$ (agar), BSDH and BSSH were I $: \mathrm{I}, \mathrm{I}: 32, \mathrm{I}: 8$ to I $: \mathrm{I} 6$ and $\mathrm{I}: 8$ to I $: \mathrm{I} 6$, respectively (Table I).

Approximate m.i.d. for guinea-pig chambers. The approximate m.i.d. values for strains BS3, BS3 (agar), BSDH and BSSH were $<20,<20,<20$ and $>2000$, respectively (Table 2).

Examination of surface antigens by gel diffusion. With an antiserum raised by BS3 infection in guinea-pig chambers, TSB washes (Penn et al., 1976) of BSDH (agar) did not produce two or three precipitation lines formed by similar extracts of BS3 (agar) (Fig. $3 a$ ). When 
Table 2. Infectivity for guinea-pig chambers of strains BS3, BS3 (agar), BSDH and $\mathrm{BSSH}$

\begin{tabular}{lccc}
\multirow{3}{*}{ Strain } & $\begin{array}{l}\text { Inoculum } \\
\text { (no. of organisms) }\end{array}$ & $24 \mathrm{~h}$ & 7 days \\
BS3 3 & 2 & $2 / 2$ & $2 / 2$ \\
& 20 & $2 / 2$ & $2 / 2$ \\
& 200 & $2 / 2$ & $2 / 2$ \\
BS3 (agar) of chambers infected $\dagger$ at:
\end{tabular}

ND, Not done.

* Figures were based on viable counts done previously on thawed suspensions, and on total counts of BS3 (agar); when checked by viable counts at the time of the experiment, the counts on the dilution corresponding to 200 organisms did not vary by more than $25 \%$ from this figure.

$\dagger$ Counts greater than 50 viable gonococci per ml chamber fluid; usually they were $10^{4}$ to $10^{6}$.

the antiserum had been adsorbed with BSDH (agar), two lines (one crescent-shaped and diffuse near the antigen well, the other straight and better defined) remained on diffusion against washes of BS3 (agar) but not against those of BSDH (agar) (Fig. $3 b$ ). Similar results were obtained if BSSH (agar) and its washes were used instead of BSDH (agar); thus BSDH (agar) and BsSH (agar) did not appear to differ antigenically.

Suspensions in saline. Strain BS3 (agar) formed a smooth suspension in saline which separated slowly, whereas BSDH (agar) and BSSH (agar) formed rough suspensions which separated rapidly.

Resistance to intracellular killing by human phagocytes. Viable and microscopic counts of cell-associated gonococci [BSSH, BSDH, BS3 (agar) and BS3] I $\mathrm{h}$ after mixing the bacteria and phagocytes and allowing them to settle on the glass surface of Leighton tubes as described by Witt et al. (1976a,b) are shown in Table 3. Some multiplication of gonococci (or declumping) must have occurred during the $\mathrm{I} h$ phagocytosis period since the viable counts in the supernatant solutions (column 2) were usually higher than those in the inoculum (column I), but no significant differences in the behaviour of organisms grown in vitro and in vivo were observed (compare Witt et al., I976a). Ingestion of gonococci was indicated by the fact that the number of viable gonococci in deposits attached to the glass in tubes containing phagocytes was much greater than the number in the control tubes without phagocytes. This was confirmed by electron microscopy of ultra-thin sections of infected phagocytes which showed that most $(\geqslant 85 \%)$ of the cell-associated organisms were intracellular. Microscopic counts of the numbers of phagocytes attached to the glass (column 3) and of cell-associated gonococci (column 4) varied and there were no consistent interstrain differences. However, BSDH organisms appeared to be more resistant to intracellular killing than strain BSSH (experiments I to 4), as indicated by the percentage of the gonococci 

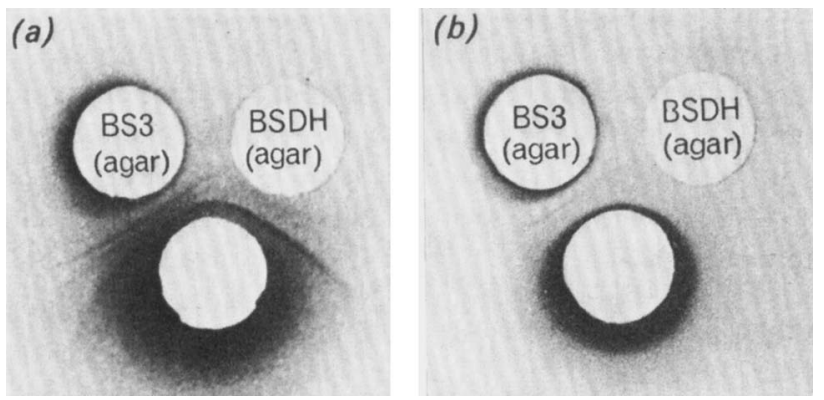

Fig. 3. Precipitation lines in gels formed by washes of BS3 (agar) and BSDH (agar) against (a) unadsorbed antiserum, and $(b)$ antiserum adsorbed by BSDH (agar).

Table 3. Resistance to intracellular killing by human phagocytes: viable and microscopic counts of BSSH, BSDH, BS3 (agar) and BS5 I $h$ after mixing with the phagocytes and settling in Leighton tubes

For methods see Witt et al. (1976a,b).

I $2 \quad 3 \quad 4 \quad \begin{gathered}5 \\ \text { Deposit: }\end{gathered}$

\begin{tabular}{|c|c|c|c|c|c|}
\hline $\begin{array}{c}\text { Expt } \\
\text { and blood } \\
\text { donor }\end{array}$ & $\begin{array}{l}\text { Inoculum: } \\
\text { IO }^{-4} \times \\
\text { viable count }\end{array}$ & $\begin{array}{l}\text { Supernatant: } \\
1^{-4} \times \\
\text { viable count }\end{array}$ & $\begin{array}{c}\text { Deposit: } \\
1^{-4} \times \\
\text { phagocyte count* }\end{array}$ & $\begin{array}{l}\text { Deposit: } \\
\text { gonococci per } \\
\text { phagocyte } \dagger\end{array}$ & $\begin{array}{l}\text { viable gon } \\
\text { as } \% \text { of } \\
\text { microscc } \\
\text { count }\end{array}$ \\
\hline I. $\mathrm{CP}$ & $\begin{array}{ll}\text { BSSH } & 7 \cdot 5 \\
\text { BSDH } & 7 \cdot 0\end{array}$ & $\begin{array}{l}17 \\
26\end{array}$ & $\begin{array}{c}4 \cdot 5 \\
19\end{array}$ & $\begin{array}{l}0.74 \\
0.50\end{array}$ & $\begin{array}{r}2 \\
\text { I I }\end{array}$ \\
\hline 2. DV & $\begin{array}{ll}\text { BSSH } & 2 \cdot I \\
\text { BSDH } & 3 \cdot 0\end{array}$ & $\begin{array}{l}\text { I I } \\
\text { I I }\end{array}$ & $\begin{array}{l}5 \cdot 4 \\
4 \cdot 3\end{array}$ & $\begin{array}{l}0 \cdot 78 \\
\mathrm{I} \cdot 3\end{array}$ & $\begin{array}{l}19 \\
53\end{array}$ \\
\hline 3. NP & $\begin{array}{ll}\text { BSSH } & \text { I } \cdot 4 \\
\text { BSDH } & 2 \cdot 4\end{array}$ & $\begin{array}{l}3 \cdot 7 \\
4 \cdot 8\end{array}$ & $\begin{array}{l}2 \cdot 1 \\
0.94\end{array}$ & $\begin{array}{l}0.71 \\
0.25\end{array}$ & $\begin{array}{l}1 \cdot 8 \\
19\end{array}$ \\
\hline 4. DV & $\begin{array}{ll}\text { BSSH } & 3 \cdot 0 \\
\text { BSDH } & 2 \cdot 8\end{array}$ & $\begin{array}{l}3 \cdot 9 \\
8 \cdot 4\end{array}$ & $\begin{array}{l}I \cdot 1 \\
0 \cdot 85\end{array}$ & $\begin{array}{l}0.11 \\
0.076\end{array}$ & $\begin{array}{l}3 \cdot 8 \\
43\end{array}$ \\
\hline $5 . \mathrm{sW}$ & $\begin{array}{l}\text { BS3 (agar) } 3.4 \\
\text { BSDH } 7.0\end{array}$ & $\begin{array}{l}24 \\
21\end{array}$ & $\begin{array}{r}r \cdot 3 \\
4 \cdot 5\end{array}$ & $\begin{array}{l}0.64 \\
0.12\end{array}$ & $\begin{array}{l}14 \\
26\end{array}$ \\
\hline 6. $\mathrm{BB}$ & $\begin{array}{l}\text { BS3 (agar) } 5.5 \\
\text { BSDH } 6.0\end{array}$ & $\begin{array}{l}\mathrm{I} 2 \\
2 \mathrm{I}\end{array}$ & $\begin{array}{l}0.9 \\
2 \cdot 7\end{array}$ & $\begin{array}{l}0.11 \\
0.13\end{array}$ & $\begin{array}{l}26 \\
26\end{array}$ \\
\hline 7. NP & $\begin{array}{l}\text { BS3 (agar) } 6.5 \\
\text { BSDH } 5 \cdot 5\end{array}$ & $\begin{array}{l}33 \\
22\end{array}$ & $\begin{array}{l}0.68 \\
I \cdot 5\end{array}$ & $\begin{array}{l}0.16 \\
0.09\end{array}$ & $\begin{array}{l}32 \\
36\end{array}$ \\
\hline 8. DV & $\begin{array}{l}\text { BS5 } 8 \cdot 5 \\
\text { BSDH I I }\end{array}$ & $\begin{array}{l}26 \\
15\end{array}$ & $\begin{array}{l}2 \cdot 6 \\
4 \cdot 6\end{array}$ & $\begin{array}{l}0.14 \\
0.19\end{array}$ & $\begin{array}{l}40 \\
25\end{array}$ \\
\hline 9. DV & $\begin{array}{ll}\text { BS5 } 12 \\
\text { BSDH } 4 \cdot 8 \\
\text { BSDH } 48\end{array}$ & $\begin{array}{r}28 \\
1 \mathrm{I} \\
210\end{array}$ & $\begin{array}{l}4 \cdot 8 \\
3 \cdot 3 \\
7 \cdot 2\end{array}$ & $\begin{array}{l}0.27 \\
0.13 \\
I \cdot 1\end{array}$ & $\begin{array}{l}54 \\
91 \\
2 \text { I }\end{array}$ \\
\hline IO. DV & $\begin{array}{ll}\text { BS5 } & 5.5 \\
\text { BSDH } & 3.9\end{array}$ & $\begin{array}{l}9 \cdot 6 \\
4 \cdot 9\end{array}$ & $\begin{array}{l}5 \cdot 4 \\
4 \cdot 8\end{array}$ & $\begin{array}{l}0.23 \\
0.045\end{array}$ & $\begin{array}{l}20 \\
20\end{array}$ \\
\hline
\end{tabular}

* About $80 \%$ polymorphonuclear phagocytes; $10^{6}$ phagocytes were added initially to each tube.

$\dagger$ By microscopic counts on at least IoO phagocytes randomly selected (including uninfected cells). Electron microscopy showed that most of the gonoccoci were intracellular.

t Total microscopic count obtained by multiplying columns 3 and 4 . 
seen associated with the phagocytes that remained viable after I $h$ phagocytosis (column 5 ). In other experiments (not shown) BSSH was killed in a similar manner to the parent strain BS. The resistance to killing of strain BS3 (agar) was similar to that of strain BSDH (experiments 5 to 7) and even when the strain adapted in vivo was examined directly without subculture (BS5) no difference between its resistance and that of BSDH was detected (experiments 8 to I0). Similar results to those shown in experiments 8 to Io were obtained when BS5 and BSDH were not conditioned in the phagocytosis medium for $\mathrm{I} \mathrm{h}$ at $37^{\circ} \mathrm{C}$ before the phagocytes were added, as in the original comparisons of the organisms grown in vivo with the parent BS strain (Witt et al., 1976a).

\section{Examination of two additional laboratory strains (AS and DS) for 'double highlight' colonies either directly or after three passages through guinea-pig chambers}

Strains AS and DS gave similar results to strain BS. After three passages through guineapig chambers more than $95 \% \mathrm{DH}$ colonies were formed by AS3 and DS3 organisms. When plated directly, AS and Ds produced mixtures of $\mathrm{DH}, \mathrm{SH}$ and $\mathrm{NH}$ colonies. Strains ASDH and ASSH were selected and stored in a manner similar to the strains derived from BS and the following properties were examined either directly or after one subculture on agar [ASDH agar) and ASSH (agar)].

Pilation. Experiments similar to those described for the types derived from strain BS showed strains As3 (agar) (I7.6 \pm 10.6 S.D. pili per organism) and ASDH (agar) (18.4 \pm 9.0 S.D. pili per organism) to be as heavily pilated as BS3 (agar) and BSDH (agar), whereas organisms of ASSH (agar) were sparsely pilated like those of BSSH (agar). As expected after passage through guinea-pig chambers, organisms of DS3 (agar) were abundantly pilated $\left(22 \cdot 3 \pm 24^{\cdot} 6\right.$ s.D. pili per organism).

Resistance to killing by human serum. As with strain BS, the chamber-grown organisms (AS3) were resistant whereas AS3 (agar), ASDH and ASSH colonies were susceptible to $50 \%$ killing at $\mathrm{I}: 8$ to $\mathrm{I}: 32$ dilution of serum (Table $\mathrm{I}$ ).

Resistance to killing by human phagocytes. Similar differences in resistance to intracellular killing to those seen for BSDH and BSSH were observed for ASDH and ASSH; ASSH was less resistant than ASDH.

\section{Examination of primary and secondary cultures of fresh urethral pus for 'double highlight' colonies}

DH colonies were observed on the initial plate culture of three fresh samples of urethral pus, but the proportion of the total colonies showing DH morphology could not be assessed accurately because of sparse gonococcal growth and the difficulty of distinguishing contaminants from $\mathrm{SH}$ or $\mathrm{NH}$ gonococcal colonies. Organisms from $\mathrm{DH}$ colonies picked from these first cultures constituted strains CS, ES and FS; they were stored as described in Methods. On first subculture of CS, ES and FS the majority of colonies were DH but 5 to $20 \%$ were $\mathrm{SH}$ or NH. After three passages through guinea-pig chambers, as described previously, CS3, ES3 and FS3 produced more than $95 \% \mathrm{DH}$ colonies when grown once on agar [CS3 (agar), ES3 (agar) and FS3 (agar)]. Strains CSDH and CSSH were prepared from CS and stored in a similar manner to the strains derived from Bs. The following properties were examined either directly or after one subculture on agar [CSDH (agar), CSSH (agar)].

Pilation. Strains Cs3 (agar) (I0.8 \pm I I $\cdot 2$ S.D. pili per organism) and CSDH (agar) (I6.4 4 I I 6 S.D. pili per organism) were as heavily pilated as BS3 (agar) and BSDH (agar), whereas organ- 
Table 4. Summary of properties of strains derived from the BS parent strain

$\begin{array}{lclccccc}\text { Strain } & \begin{array}{c}\text { Predominant } \\ \text { colony type }\end{array} & \text { Pilation } & \begin{array}{c}\text { Chamber } \\ \text { infectivity }\end{array} & \begin{array}{c}\text { Resistance } \\ \text { to phagocyte } \\ \text { killing }\end{array} & \begin{array}{c}\text { Resistance } \\ \text { to serum } \\ \text { killing }\end{array} & \begin{array}{c}\text { Saline } \\ \text { suspension }\end{array} & \begin{array}{c}\text { Surface } \\ \text { antigens* }\end{array} \\ \text { BS3 } & \text { DH } & \text { Variable } & \text { High } & + & + & \text { NA } & \text { NA } \\ \text { BS3 (agar) } & \text { DH } & \text { Heavy } & \text { High } & + & - & \text { Smooth } & 2 \\ \text { BSDH } & \text { DH } & \text { Heavy } & \text { High } & + & - & \text { Rough } & \text { None } \\ \text { BSSH } & \text { SH } & \text { Sparse } & \text { Low } & - & - & \text { Rough } & \text { None }\end{array}$

+ , Resistant; - , susceptible; NA, not applicable.

* In gel diffusion against antiserum to BS3 adsorbed with BSDH.

isms of CSSH (agar) were sparsely pilated. Strains ES3 (agar) (I0.7 $\pm 8 \cdot 8$ S.D. pili per organism) and FS3 (agar) (I0.0 $\pm 6 \cdot 0$ S.D. pili per organism) were also heavily pilated.

Resistance to killing by human serum. Strain CS3 showed a degree of resistance to human serum similar to those of strains BS3 and AS3. However, in contrast to the BS and AS systems, strains CS3 (agar), CSDH and CSSH grown in vitro retained resistance to human serum (Table I).

\section{DISCUSSION}

The results obtained for the various strains derived from the parent BS strain of the gonococcus are summarized in Table 4. They suggest that adaptation to growth in vivo in guinea-pig subcutaneous chambers involves both selection and phenotypic change.

The evidence for selection, which had been indicated by previous comparisons of strain BS with the strain grown in vivo in phagocytosis experiments (Witt et al., I976a), received strong support from experiments which followed from the recognition of the DH colonies in populations containing $\mathrm{SH}$ and $\mathrm{NH}$ colonies. First, almost all the colonies formed by strain BS3, grown in vivo, were DH, whereas only a small proportion of those formed by the parent strain BS were $\mathrm{DH}$, the rest being $\mathrm{SH}$ or $\mathrm{NH}$. Second, separation and comparison of BSDH and BSSH strains showed that the former resembled the strain grown in vivo examined either directly or after one subculture on agar [BS3 (agar)] in that it was heavily pilated, highly infective for guinea-pig chambers (Table 2) and resistant to killing by human phagocytes (Table 3). The latter two properties may be connected since it appears that the main defence mechanism in guinea-pig chambers is a phagocytic rather than a humoral mechanism (Veale et al., 1977). In contrast, strain BSSH had very few pili (although in one of eight clones examined, significant numbers of pili were observed), did not infect guinea-pig chambers in doses 100 to $1000-$ fold greater than the infective dose for BSDH (Table 2) and was far more susceptible to killing by phagocytes (Table 3). Unlike the resistant strain grown in vivo (BS3), the DH colony type selected in vitro (BSDH) and BSSH were susceptible to killing by human serum. That this difference in resistance was phenotypic was indicated by the fact that the resistance of strain $\mathrm{BS}_{3}$ was lost after one subculture on agar (Table I), i.e. in approximately 20 cell generations. This was probably too short a time for mutation and selection to have occurred.

Surface washes of BS3 (agar) contained one or two antigen sthat were not found to a significant extent or were absent from similar preparations from BSDH and BSSH. These antigens are probably not connected with pili because BSDH is as pilated as BS3 (agar). On the other hand, if the antigens are located at the gonococcal surface, they may be connected with the ability of BS3 (agar) to form smooth saline suspensions in contrast to the rough suspensions formed by BSDH and BSSH (and Kellogg types I and 2; Kellogg et 
al., I963; Jephcott \& Reyn, I97I). Although these antigens do not appear to determine the resistance to human serum, since BS3 (agar) was as sensitive to this agent as BSDH and BSSH, small changes in structure may affect serum sensitivity without influencing antigenicity. Gibbs \& Roberts (1975) noted that exponential phase gonococci of Kellogg type 2, which were harvested from chick embryo allantoic fluid, formed smooth suspensions in saline and showed some resistance to human serum, although comparisons with the degrees of resistance obtained in the present study are difficult since their serum was diluted I: 10 and other test conditions were different. The capacity of gonococci to acquire resistance to human serum, which is noted here for organisms grown in guinea-pig chambers and by Ward et al. (1970) for gonococci in urethral pus, is supported by recent results of McCutchan, Levine \& Braude (1976). Since Kellogg types I and 2 organisms were more resistant to killing by human serum than types 3 and 4 , and survivors from types I and 2 populations were more resistant than the parent population, they prepared a highly resistant population by eight serial passages in serum. Although the high resistance of this population was restricted to the serum in which the population was prepared and did not appear to be as strong as that reported here for BS3, it was, like the latter, quickly lost on subculture on agar (McCutchan et al., I976). The resistance to human serum, which appears to be phenotypically acquired, may be important in the pathogenesis of gonorrhoea in humans, especially in the disseminated disease (Penn et al., 1976; McCutchan et al., 1976), although resistance to humoral factors seems of little significance in infection of guinea-pig chambers (Veale et al., 1977; Penn et al., 1977).

As with strain BS, laboratory strains AS and DS produced mixtures of DH, SH and NH colonies; after passage through guinea-pig chambers AS3 and DS3 formed predominantly DH colonies. Pilation and resistance to human serum for AS3, AS3 (agar), ASDH and ASSH followed the same pattern as for strains derived from BS, and also ASSH was less resistant than ASDH to killing by human phagocytes.

Three fresh samples of urethal pus showed DH colonies on the first culture and those colonies produced 80 to $85 \% \mathrm{DH}$ colonies on the second culture, the remainder being $\mathrm{SH}$ and NH. Passage of organisms from the second culture produced CS3, ES3 and Fs 3 which like BS3 formed more than $95 \% \mathrm{DH}$ colonies on agar, the organisms of which were heavily pilated. Similarly, CSDH gonococci were heavily pilated whereas strain CSSH was sparsely pilated. However, examination of the cs system for serum resistance did not yield the same pattern as for the BS and AS systems. Like BS3 and AS3, CS3 was resistant to human serum but, unlike BS3 (agar), AS3 (agar) and the DH and SH strains from BS and AS, strains $\operatorname{Cs} 3$ (agar), CSDH and CSSH were also resistant to killing. One explanation is that the pool of human serum did not possess the 'natural antibody' for the cs system. Killing by serum appears to depend on complement (Glynn \& Ward, 1970; Ward et al., 1970; McCutchan et al., 1976) and the specific antibody might be necessary for activation of complement. Strains resistant to killing by human serum after subculture were isolated from urethral pus (Ward et al., 1970). Also, in parallel with the similarity of AS and BS strains and their difference from CS strains with respect to serum killing, AS and BS strains cross-immunized in guinea-pig chambers but did not cross-immunize with cs (Penn et al., 1977). This pattern was repeated when the three strains were exposed to the sera from guinea pigs which had been immunized by each of the strains (Penn et al., 1977). These observations indicate that CS strains were antigenically different from strains AS and BS. Obviously, if the specific natural antibody to sensitize the CS system were absent from the serum pool, then any phenotypic loss from Cs3, on subculture, of a surface component which interferes with serum lysis would not be detected. 
Two main conclusions may be drawn from this work. First, as regards the pathogenicity of gonococci, the conditions in vivo select genotypes which resist killing by phagocytes and may produce phenotypes which resist the killing action of complement and natural antibody. Second, the detection of DH colonies may be a more reliable index of the pathogenicity of a gonococcal isolate or laboratory strain than systems used previously. Published photographs of colony types designated by Kellogg's system (Kellogg et al., 1963, 1968; Jephcott \& Reyn, I97I ; Brown \& Kraus, 1974) do not always correspond and the description of light and dark variants of types I and 2 (Brown \& Kraus, I974) adds to the difficulties of distinguishing different members of this system. In this paper we have described a simple lighting system that distinguishes the DH colonies that are associated with: (i) gonococci obtained directly from urethral pus; (ii) gonococci obtained directly from guinea-pig chambers after selection from parent strains containing $\mathrm{SH}$ and $\mathrm{NH}$ colonies; (iii) the resistance of gonococci to intracellular killing by human phagocytes; (iv) high infectivity for guinea-pig chambers; and (v) heavy pilation of their contained organisms in contrast with those from SH colonies which usually have few pili, although sometimes significant numbers have been observed. On the other hand, resistance to human serum, possession of certain antigens and ability to produce smooth suspensions in saline are not associated with $\mathrm{DH}$ character; appropriate phenotypic change in vivo may produce these properties. The DH colony character would encompass the potentially pathogenic members of both Kellogg type I [small colonies of pilated organisms found in most clinical isolates (Kellogg et al., I963; Jephcott \& Reyn, I971)] and type 2 [colonies with a shiny surface and defined edge, and heavy pilation of the organisms (Kellogg et al., 1963, I968; Jephcott \& Reyn, I97I ; Reyn, Jephcott \& Ravn. I97I ; Kraus \& Glassman, 1974)] and might be a useful alternative, single category.

We are indebted to Mrs J. Litchfield, Mrs S. Sutton and Mr M. Cattermole for technical assistance. C. W. Penn is a Beit Memorial Fellow.

\section{REFERENCES}

Brown, W. J. \& Kraus, S. J. (1974). Gonococcal colony types. Journal of the American Medical Association 228, 862-863.

GibBS, D. L. \& RoBERTs, R. B. (1975). The interaction in vitro between human polymorphonuclear leucocytes and Neisseria gonorrhoeae cultivated in the chick embryo. Journal of Experimental Medicine I4I, I55-I7I.

GlynN, A.A. \& WARD, M. E. (1970). Nature and heterogeneity of the antigens of Neisseria gonorrhoeae involved in the serum bactericidal reaction. Infection and Immunity 2, I62-I 68.

JephCott, A. E. \& ReYN, A. (I97I). Neisseria gonorrhoeae: Colony variation. I. Acta pathologica et microbiologica scandinavica B79, 609-6r4.

Kellogg, D. S., Jr, Peacock, W. L., JR, Deacon, W. E., Brown, L. \& Pirkle, C. I. (1963). Neisseria gonorrhoeae. I. Virulence genetically linked to clonal variaticu. Journal of Bacteriology 85, 1274-1 279.

Kellogg, D. S., JR, Cohen, I. R., Norins, L. C., SChroeter, A. L. \& Reising, G. (1968). Neisseria gonorrhoeae. II. Colonial variation and pathogenicity during 35 months in vitro. Journal of Bacteriology 96, 596-605.

Kraus, S. J. \& Glassman, L. H. (1974). Scanning electron microscope study of Neisseria gonorrhoeae. Applied Microbiology 27, 584-592.

Mahoney, J. F., van Slyke, C. J., Cutler, J. C. \& Blum, H. L. (1946). Experimental gonococcic urethritis in human volunteers. American Journal of Syphilis, Gonorrhoea and Venereal Diseases 30, I-39.

McCutchan, J. A., Levine, S. \& Braude, A. I. (1976). Influence of colony type on susceptibility of gonococci to killing by human serum. Journal of Immunology $116,1652-1655$.

Novotny, P., ShoRT, J. A. \& WALKer, P. D. (1975). An electron microscope study of naturally occurring and cultured cells of Neisseria gonorrhoeae. Journal of Medical Microbiology 8, 413-427. 
Penn, C. W., Sen, D., Veale, D. R., Parsons, N. J., Smith, H. \& Witt, K. (1976). Morphological, biological and antigenic properties of Neisseria gonorrhoeae adapted to growth in guinea-pig subcutaneous chambers. Journal of General Microbiology 97, 35-43.

Penn, C. W., Parsons, N. J., Sen, D., Veale, D. R. \& Smith, H. (1977). Immunization of guinea pigs with Neisseria gonorrhoeae: strain specificity and mechanisms of immunity. Journal of General Microbiology roo, I 59-I66.

ReYn, A., JEPHCOTt, A. E. \& RAVN, H. (197I). Neisseria gonorrhoeae. Colony variation. II. Acta pathologica et microbiologica scandinavica $\mathbf{B}_{79}, 435-436$.

SMiтH, H. (1972). The little known determinants of microbial pathogenicity. Symposium of the Society for General Microbiology 22, I-24.

Veale, D. R., Smith, H., Witt, K. \& Marshall, R. B. (1975). Differential ability of colonial types of Neisseria gonorrhoeae to produce infection and an inflammatory response in subcutaneous perforated plastic chambers in guinea pigs and rabbits. Journal of Medical Microbiology 8, 325-335.

Veale, D. R., Sen, D., Penn, C. W., Finch, H. \& Smith, H. (1977). Interaction of Neisseria gonorrhoeae with guinea pig defence mechanisms in subcutaneously implanted chambers. FEMS Microbiology Letters (in the Press).

WARD, M. E., WATt, P. J. \& GLYNN, A. A. (1970). Gonococci in urethral exudates possess a virulence factor lost on subculture. Nature, London 227, 382-384.

Witt, K., Veale, D. R., Finch, H., Penn, C. W., Sen, D. \& Smith, H. (1976a). Resistance of Neisseria gonorrhoeae grown in vivo to ingestion and digestion by phagocytes of human blood. Journal of General Microbiology 96, 341-350.

Witt, K., Veale, D. R. \& Smith, H. (1976b). Resistance to ingestion and digestion of Neisseria gonorrhoeae by phagocytes of human buffy coat. Journal of Medical Microbiology $\mathbf{9}, \mathbf{I}-\mathbf{I} 2$. 